\title{
El arco de San Isidoro de Oviedo. La destrucción del patrimonio monumental ovetense en el primer tercio del siglo XX. Parte II
}

Ana María Herrero Montero Archivo Municipal de Oviedo

RESUMEN:

El 10 de septiembre de 1925, el Ayuntamiento de Oviedo aprueba la instalación en el Campo de San Francisco del arco de la portada de San Isidoro, último vestigio de aquella iglesia románica. Este artículo, en un viaje a través del tiempo, pretende dar explicación de cómo se llegó a esta situación basándose en los documentos que sobre esta cuestión obran en los distintos archivos ovetenses, a la vez que se presentan otras discutidas actuaciones en materia de destrucción del Patrimonio monumental ovetense en los comienzos del s. XX.

\section{PALABRAS CLAVE:}

Oviedo. Historia. San Isidoro El Real. Patrimonio monumental. Urbanismo (Oviedo).

\section{ABSTRACT}

On the $10^{\text {th }}$ of September, 1925, the Oviedo City Council authorized the installation of the last remains of the Romanesque Church of San Isidoro, its arched portal, in the Campo de San Francisco. On a journey through time, this article aims to explain how this situation arose, with the help of documents from the Oviedo archives, while, in a second part, outlining other controversial acts of destruction of Oviedo's monumental heritage at the beginning of the $\mathrm{XX}^{\text {th }}$ century.

\section{KEY WORDS:}

Oviedo. History. San Isidoro el Real. Monumental heritage. Urban planning (Oviedo). 
Antes de continuar en este artículo con el estudio de las actuaciones municipales que certifican que, lamentablemente, el derribo de San Isidoro el Real no fue un caso aislado en el panorama ovetense, al ser muchos los monumentos que vieron terminar sus días en el comienzo del siglo $X^{1}$, me permito realizar unas puntualizaciones a lo ya publicado a la luz de nuevas informaciones localizadas en la prensa local.

Así, en el artículo precedente, indicaba: "Cuándo y cómo fue adquirido el arco y el precio de compra no consta en ningún documento; siempre se habla del Centro de Estudios Asturianos como su propietario pero sin aportar más datos $»^{2}$. Pues bien, el diario Región, bajo el titular "Dos trabajos de Víctor Hevia», anunciaba lo siguiente: «Hace tres años (próximamente) el Ayuntamiento cedió la vieja iglesia a la Cooperativa de obreros para que la deshicieran por cuenta de ellos, quedándose con la piedra del edificio.

El entonces presidente del Centro de Estudios Asturianos, don Aurelio del Llano pasó por las obras de demolición, con objeto de mirar si había alguna piedra digna de ser recogida, reuniéndose el Centro de Estudios a fin de tratar el rescate del arco que fue adquirido en 700 pesetas» ${ }^{3}$

Asimismo, el artículo nos informa de la única condición exigida por el Centro al Ayuntamiento de Oviedo para el regalo del Arco: que se colocara una piedra en la que constara que fue donado por el Centro, piedra que desconocemos si se colocó en su momento pero que, en la actualidad, no existe. También se indica que se colocará en el arco "su historial" y el propio articulista recomienda que se hagan unos caminos para poder acercarse a admirar los capiteles "Y si no se hacen, los hará el público" advierte. Tampoco existe constancia de que llegara a emplazarse alguna lápida o placa conmemorativa con "el historial», afortunadamente sí que po-

\footnotetext{
En este estudio no trataremos lo sucedido con el convento de San Francisco, ni de la iglesia de San Juan el Real dado que sus intervenciones comenzaron en el s. XIX. V. María Cruz Morales Saro, «El desarrollo urbano de Oviedo y las demoliciones y derribos del patrimonio arquitectónico en el siglo XIX", en Liño, 1, Oviedo, 1980, pp. 85-98.

2 Ana María Herrero Montero, «El arco de San Isidoro de Oviedo. la destrucción del patrimonio monumental ovetense en el primer tercio del siglo XX. Parte I», en Liño, 22, Oviedo, 2016, p. 19.

3 Región, viernes 26 de febrero de 1926. Información facilitada por don Faustino Busto.
}

demos acercarnos tranquilamente al arco por el camino recientemente acondicionado.

Por otra parte, el mismo diario va comentando en años sucesivos el acondicionamiento de la plaza de San Isidoro tras el derribo y, en uno de sus artículos, nos llega la explicación del espacio porticado que aparece en las imágenes de la época rodeando el Paraguas; esta obra se debió: "...porque el ingeniero municipal, en su afán de introducir modalidades en sus proyectos, [ha] construido un paraguas en [el re] ferido mercado que no sirve más que de estorbo porque [los] días de lluvia las pobres [leche]ras, que son las que acuden [con] su mercancía a la citada [plaza] se mojan más que si es[tuvie]ran a la intemperie.

Esto ha podido compro[bar] la comisión municipal, y [para] poner remedio al mal se [man]dó construir unos coberti[zos al]rededor de la citada plaza [pa]ra que tanto las vendedoras [co]mo las compradoras pue[dan] guardarse del agua $n^{4}$. Queda claro que no siempre finalidad, función y estética van de la mano en lo que se refiere a las obras municipales.

Y retomando la cuestión del tratamiento dado por el Ayuntamiento al patrimonio monumental, nos encontramos con una pauta de actuaciones que, vista desde una perspectiva actual, sería cuando menos cuestionable:

\section{Casa del deán Payarinos}

En la actual Corrada del Obispo, entonces llamada Plazuela de Álvarez Acevedo, el deán don Benigno Rodríguez Pajares planeó, en 1899, construir su vivienda particular derribando para ello el antiguo edificio existente llamado Casa del Chantre, que había servido para dependencias adjuntas del Obispado. Con tal fin solicita la alineación para el nuevo edificio, alineación que informa favorablemente el arquitecto municipal don Juan Miguel de la Guardia, quien sugiere que, dadas las dificultades para realizar una buena alineación entre las calles San José y San Vicente, dificultades que consisten únicamente en una expropiación de los terrenos del deán para el retranqueo de las fachadas, propone una solución que disimule y suavice el martillo "por medio de rotondas que al mismo tiempo que dan motivo a formas arquitectónicas de mayor grandiosidad

\footnotetext{
$4 \quad$ Región, miércoles 7 de enero de 1931.
} 
para el edificio, contribuyen a dar más cumplida satisfacción a las exigencias del ornato público" ${ }^{5}$; solución que aprueba la Corporación el 9 de diciembre de 1899. Lo que no consta en el informe es que será este mismo arquitecto de la Guardia el encargado de la construcción del edificio, según los planos firmados por él de fecha abril de 1900 que acompañan el proyecto de construcción ${ }^{6}$. La plazuela quedó como estaba, pero el edificio fue motivo de admiración y comentarios para los ovetenses que veían en su tamaño una competición encubierta entre los miembros del Cabildo ${ }^{7}$.

\section{Colegio de San Gregorio}

El antiguo colegio de San Gregorio, llamado de los Pardos por el color de la beca, fue una fundación del Arzobispo Valdés Salas. En enero de 1836 el Ayuntamiento de Oviedo solicitó, a instancias del Capitán de la Guardia Nacional de Oviedo, el edificio del Colegio para cuartel de la Milicia Nacional, solicitud aprobada por Real Orden de 10 de Febrero, en la que se hacía constar que, en el momento en que la Ciudad contara con otro edificio para cuartel, el Colegio de San Gregorio sería puesto en manos de la Comisión Provincial de Instrucción Primaria $^{8}$, como así aconteció en junio de 1844, fecha en la que el Municipio le entregó a la citada Comisión las llaves del edificio con destino a Escuela Normal de Maestros ${ }^{9}$. Según relata Canella ${ }^{10}$, el Patrono del Colegio, el Señor Duque de Berwick y Alba, tras esta entrega, reclamó al Gobierno el edificio y, después de varias resoluciones, en 1846 la propiedad volvió a sus manos, para ser inscrita en el Registro de la Propiedad de Oviedo a favor de los Herederos de la casa ducal patronal en 1874 y 1893. Poco

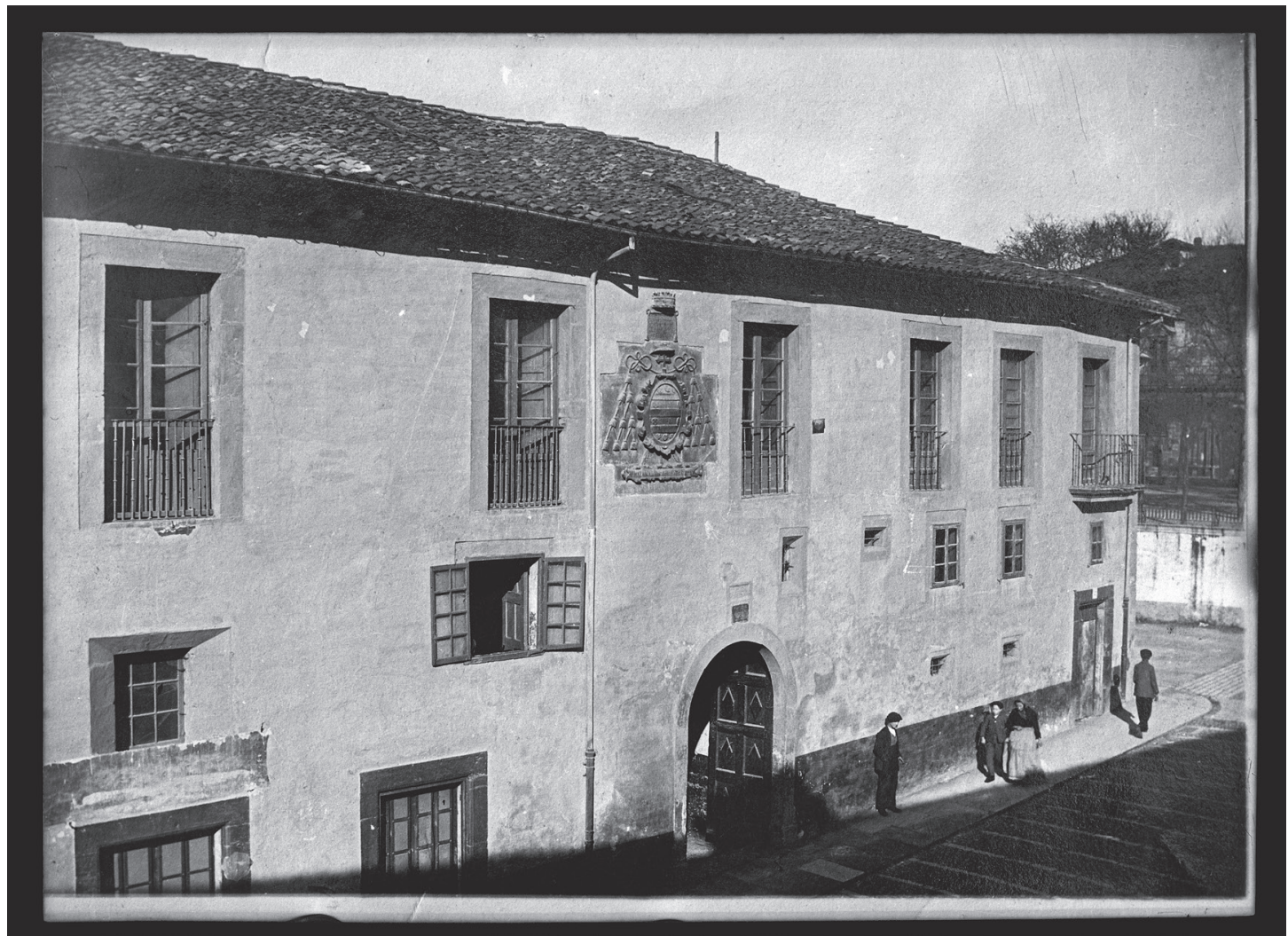

Fig. 1. Colegio de San Gregorio o de los Pardos. Luis Muñiz Miranda. c. 1894. AMO: Colección Armán, P0119.

AMO: $1-1-3-8$

AMO: 1-1-3-9.

José Fernando González Romero, "La “Casa del Deán Payarinos” en Oviedo: sede del Conservatorio de Música ", en BIDEA, 159, 0viedo, 2002, pp. 43-77.
AM0: B-9-8.

9 Acta del Ayuntamiento de 18 de junio de 1844 (AMO: A-140 f. 45v.-46r.).

10 Fermín Canella y Secades, Historia de la Universidad de Oviedo y noticias de los establecimientos de enseñanza de su distrito, $2^{\text {a }}$ ed., Imprenta de Flórez, Gusano y Compañía, Oviedo, 1903, pp. 25-33 y 296-299. 
después, los herederos de Alba vendieron la huerta y el edificio colegiales, y el nuevo dueño derribó Colegio y dependencias, vendiendo otra vez el solar al Banco Asturiano de Industria y Comercio, que edificó allí su sede principal con planos de don Juan Miguel de la Guardia de fecha abril de $1900^{11}$. En 1911 el edificio sufrió desperfectos importantes por un incendio y se solicitó licencia para su reconstrucción bajo la dirección del arquitecto don Manuel Bobes con arreglo a los planos ya existentes de 1900 de don Juan Miguel de la Guardia ${ }^{12}$.

\section{Casa de Cueto}

Con fecha 20 de mayo de 1911 se concede licencia al Ministerio de Instrucción Pública y Bellas Artes para la construcción de un edificio destinado a Laboratorio de la Facultad de Ciencias de la Universidad de Oviedo ${ }^{13}$. De dicho edificio no se conserva el expediente de construcción, únicamente la petición de una variación provisional en el cierre del solar solicitada por el rector don Fermín Canella en $1913^{14}$.

Según el propio Canella, en este solar se encontraba la casa construida en 1730 por la familia Fernández Cueto, lo que dio lugar a que la plaza se llamara, en el s. XVIII, Plazuela de Cueto, y allí habitaba el Regidor perpetuo don José Gabriel Fernández Cueto ${ }^{15}$. Esta información es aceptada y recogida en la bibliografía posterior, de forma que se da por bueno no sólo que la casa fue construida por la familia Cueto en 1730, sino que, incluso, fue el propio regidor don José Gabriel Fernández Cueto el encargado de su construcción ${ }^{16}$. Sin embargo, en 1730 don José Gabriel Fernández Cueto no había nacido y su padre, don Domingo Antonio Fernández Cueto consta como empadronado en 1731 en la parroquia de Santiago de Villapedre de Navia, según figura en la Justificación de Hidalguía

11 AM0: 1-1-64-30. Datos de su vida y obra en: María Cruz Morales Saro, «Juan Miguel de la Guardia (Ontaneda, Cantabria, 1849-0viedo, 1910)», en Artistas asturianos. X, Arquitectos, Hércules Astur, Oviedo, 2002. AMO: 1-1-64-12.

AM0: A-197 f. 70 v.

AM0: 1-1-51-24.

15 Fermin Canella y Secades, Oviedo: Guía, Est. Tip. De Vicente Brid, Oviedo, 1888, pp. 103-104.

16 José Ramón Tolivar Faes, Nombres y cosas de las calles de Oviedo, Ayuntamiento de Oviedo, 1992, pp. 546547. que presenta en $1737^{17}$ para constar como hidalgo en el padrón de ese mismo año en la calle de la Puerta Nueva, donde reside con su padre Matías $^{18}$. Todavía en 1744 vivía don Domingo Antonio en la calle Puerta Nueva, apareciendo ese año, por primera vez, su hijo José ${ }^{19}$. Habrá que esperar a 1751 para que la familia (Domingo Antonio con sus hijos José, Domingo y Rafael) figure como residente en la casa de la plaza de Riego ${ }^{20}$, entonces llamada calle de los Pozos. Los límites de dicha propiedad están claramente señalados en el Catastro de Ensenada (1753) en la relación de bienes de don Domingo Antonio Fernández Cueto: Propietario de una casa lindante con la Universidad, con una panera y un pajar, de un bergantín y de un cuarto de un patache (embarcación entre un bergantín y una goleta), entre otros. Igualmente, en la Respuesta 32 del Catastro, figura, en distintos apartados, como mercader, abastecedor del aceite de ballena, Tesorero de la Universidad, administrador del Marqués de Valdecarzana, depositario del arbitrio del Principado y Tesorero general de las Bulas del Obispado ${ }^{21}$.

Según datos de la Doctora María Ángeles Faya la casa de la calle Pozos fue comprada en 1746 por la familia Fernández Cueto a don Nicolás González Arango ${ }^{22}$. Es en esta casa donde se establecerán definitivamente los Fernández Cueto, y así, en el Padrón de 1766, residen en ellas Joseph y sus hermanos Domingo, Nicolás, Lorenzo y Juan Crisóstomo «hixos lexítimos de don Domingo Antonio Fernández Cueto difuntom ${ }^{23}$.

\section{Acueducto de los Pilares}

El Acueducto de los Pilares formó parte de la gran obra de ingeniería que se gestó en Oviedo a finales del s. XVI para transportar el agua de los manantiales del monte Naranco hasta el centro de la ciudad. Comenzado por Juan de Cerecedo "el joven", en 1572, a su muerte en

\footnotetext{
7 AMO: B-27-2 f. 481-494.

AMO: B-46-2 f. 43v.-44r.

AM0: B-46-4 f. 37 r. y v.

AM0: B-44-8 f. 32v.

Catastro B-130 f. 1.452r. - 1.461v. y B-129.

22 M. a Ángeles Faya Díaz, "Patrimonio económico y valores nobiliarios de la oligarquía ovetense a fines del Antiguo Régimen", en Las ciudades españolas en la Edad Moderna: oligarquías urbanas y gobierno municipal, KRK, Oviedo, 2014, p. 333.

23 AMO: B-47-1 f. $81 \mathrm{v}$.
} 


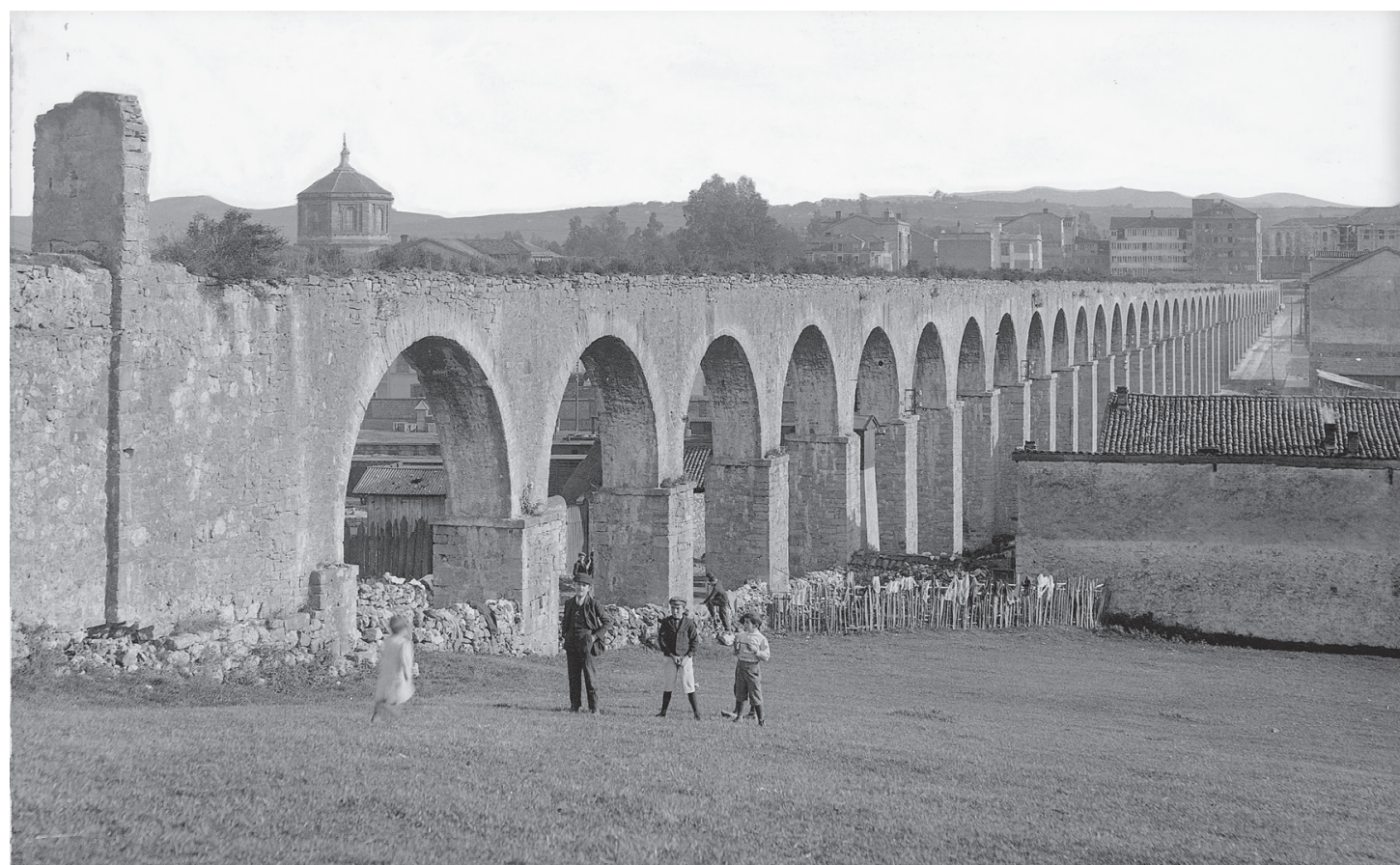

Fig. 2. Vista del Acueducto de los Pilares. Fototipia Thomas. AMO: P-00544.

1580 le sucedió Gonzalo de la Bárcena, quien tuvo que derribar todos los arcos por deficiencias de cimentación y planeamiento, de modo que a finales de 1587 se reinició la construcción del acueducto con Gonzalo de la Bárcena, dirigiendo la obra como maestro fontanero, y Pedro de la Bárcena, como maestro de la obra. Finalmente, a mediados de 1591, se dio por terminada la obra correspondiente al Acueducto ${ }^{24}$.

En 1875 se inauguró la nueva traída de aguas de los cuatro manantiales de la falda Sur del Naranco abandonándose el uso del antiguo Acueducto de los Pilares.

El 24 de enero de 1902 don Mariano Lapeña, con el fin de facilitar la urbanización de los terrenos de "Llamaquique», se ofrece para derribar por su cuenta el Acueducto de los Pilares sin más contrapartida que el aprovechamiento de los materiales, haciendo también por su cuenta el trozo de la calle proyectada paralela a dichos Pilares ${ }^{25}$. El informe del arquitecto municipal, don Juan Miguel de la Guardia, de 30 de junio de 1902, no podía ser más favorable al derribo, aunque con cierta prudencia en la redacción describiendo: "Dicha fábrica de sólida construcción y elegantes proporciones, aunque no puede considerarse como un monumento

24 AMO: Libro Viejo de Vitoria (1568-1600) C-26.
25 AMO: 1-1-77-83. artístico ni histórico, es de un efecto agradable y pintoresco, y constituye una nota característica y simpática de la antigua Ciudad. Fuera de estas condiciones, que pueden considerarse de un orden puramente moral, no existe realmente ningún otro fundamento que aconseje la conservación de dicha obra». Por otra parte, lo consideraba un impedimento para el crecimiento natural de la ciudad, para el ensanche de la estación y un gasto su conservación y su demolición en un futuro; $y$, por si a alguien le quedaran dudas sobre su opinión, se apresura a adjuntar el presupuesto de los aprovechamientos del derribo ${ }^{26}$.

Para reforzar más la postura a favor del derribo, varios concejales presentan el 30 de septiembre de ese mismo año una moción a favor del derribo "teniendo en cuenta la inutilidad de los arcos conocidos por Los Pilares y que nada benefician al ornato de la población". Sin embargo, y pese a las presiones, la Comisión de

${ }^{26}$ Que por esas fechas el arquitecto municipal estaba en una postura de renovación urbana sin contemplaciones, lo podemos deducir no sólo por este informe, sino también por el que presenta a estudio de la corporación, en sesión de 29 de diciembre de 1905, calificado como "extenso y razonado informe" en el que para mayor viabilidad de la Plaza mayor proponía "la desaparición de la iglesia de San Isidoro". AMO: A-190 f. 156v.-157r. 
Policía Urbana consideró que no era necesario dicho derribo, de forma que, en la sesión de 21 de noviembre de 1902 «ante la falta de armonía de las opiniones del arquitecto y de la Comisión", se llevó a cabo una votación ganando por 13 votos a 5 el dictamen de la Comisión ${ }^{27}$.

Una petición de la Compañía de los Caminos de Hierro del Norte, de 4 de octubre de 1905, solicitando del Ayuntamiento una resolución en el sentido de si se llevará o no a cabo el derribo del acueducto como paso previo para la ampliación de vías y andenes de la estación, reabre la polémica. Esta vez las opiniones de la Comisión de Policía Urbana y del arquitecto municipal son coincidentes, y en sesión de 24 de noviembre, se aprueba el derribo, con la excepción de dos concejales que consignan expresamente su voto en contra ${ }^{28}$.

La Comisión Provincial de Monumentos, en sesión de 27 de noviembre de 1905, decide elevar un recurso de alzada ante el Gobierno Civil contra el acuerdo de demolición de los Pilares, con traslado a las Reales Academias de la Historia y de Bellas Artes de San Fernan$\mathrm{do}^{29}$. Asimismo, presenta una protesta ante el Ayuntamiento al día siguiente firmada por su Vice-presidente, don Fermín Canella, quien, como vecino y Cronista de Oviedo, también había presentado una exhaustiva carta de protesta en la que exponía la historia del acueducto, desmontaba los argumentos a favor de su demolición y apelaba a la conservación de los monumentos como memoria de su pasado y seña de identidad de una ciudad; dicha carta fue publicada integramente en la edición del Correo de Asturias del 2 de diciembre ( $\mathrm{n}^{\circ}$ 4719) ocupando toda la primera página. Ante estos recursos y tras encendido debate, el Ayuntamiento, en sesión de 1 de diciembre de 1905, acuerda reenviar el expediente a las Comisiones de Policía Urbana e Instrucción Pública ${ }^{30}$.

En paralelo, el Ayuntamiento decidió pulsar la opinión pública, y así nos encontramos una carta del Comité de la Federación Local del Centro de Sociedades Obreras contestando a un oficio municipal sobre su opinión en relación al derribo del acueducto en la que afirman su oposición al derribo salvo "si el mantenimien-

AM0: A-187 f. 138v.-139r.

28 Votaron en contra los concejales Fernández Llana y López Planas (AM0: A-190 f. 143v.-144r.)

29 MAA: Actas de la Comisión Provincial de Monumentos, años 1904 a 1932. Caja 83730-2.

30 AMO: A-190 f. 146v.-147r. to de los Pilares significa el no ensanche de la Estación y el retraimiento de los propietarios de esa zona para edificar ${ }^{31}$.

En cualquier caso, la respuesta del Gobernador Civil fue contundente y el 15 de enero de 1906 acordó suspender el acuerdo municipal de derribo, y el 3 de febrero comunicó la real orden de 24 de enero que anula definitivamente el acuerdo municipal, quedándose enterada la Corporación en sesión de 9 de febrero de $1906^{32}$.

El Ayuntamiento, sin embargo, no se da por vencido y retoma la cuestión intentando, en el mes de junio, que los Ministros de Gracia y Justicia, don José María Celleruelo, y de la Gobernación, don Benigno Quiroga L. Ballesteros, intercedan ante el Ministro de Instrucción Pública y Bellas Artes, don Alejandro San Martín y Satrústegui, quien se limitó a contestar a ambos ministros "que la dicha Real Orden se hizo con todos los elementos de juicio que requieren las disposiciones vigentes en la materia", lo que se apresuraron a comunicar a un decepcionado alcalde de Oviedo que lo comunica el 13 de julio a una no menos decepcionada corporación ${ }^{33}$.

Pasan los años, y, una vez más, la cuestión vuelve a ser puesta sobre la mesa; en este caso son los propios concejales quienes presentan, en la sesión de 2 de diciembre de 1910, una moción a favor del derribo siempre y cuando la Compañía de Ferrocarriles y los particulares que se puedan beneficiar del mismo se comprometan y formalicen previamente las mejoras a redundar "en provecho del pueblo". La moción es aprobada por unanimidad. Y, de nuevo, la reclamación de don Fermín Canella, en esta ocasión como rector de la Universidad y Cronista de Oviedo ${ }^{34}$, sin que se vuelva a tratar del derribo en las sesiones posteriores.

Cuatro años más tarde, el 23 de noviembre de 1914, el concejal Teodomiro Menéndez pregunta al Alcalde si por fin se van a derribar los Pilares lo que proporcionaría trabajo a los obreros en paro. Tras una exposición, por parte de varios concejales, de los acuerdos anteriormente adoptados, se comisiona al Alcalde para que haga las gestiones oportunas para efectuar su derribo ${ }^{35}$. Sin embargo, el 11 de enero co-

\footnotetext{
AM0: 1-1-77-83.

AM0: A-191 f. $18 \mathrm{r}$.

AMO: 1-1-77-83 y A-191 f. 90r.

AM0: 1-1-77-113 y A-196 f. 210v.-211r.

AMO: A-200 f. 255r.
} 
mienza el derribo sin previo aviso; ante esta situación, ya de facto, las reacciones son varias, de forma que mientras parte de la prensa lo recibía con alborozo, como El Noroeste ${ }^{36}$, otra parte se lamentaba amargamente (El Carbayón y El Correo de Asturias, en sus ediciones de 12 de enero y de 13 de enero respectivamente).

Contra todo pronóstico, en la sesión del Ayuntamiento el derribo de los Pilares suscita varias interpelaciones de los concejales aisladas y sin conexión unas con otras: una de ellas preguntando al Alcalde qué gestiones había realizado de las encomendadas (cuestión esta que quedó sin contestar ante la ausencia del directamente interpelado Alcalde); otra sugiriendo que se conservaran al menos tres arcos; otra proponiendo levantar un muro en el Campo de San Francisco con los materiales obtenidos; únicamente el concejal Guisasola solicita la suspensión del derribo en tanto no se sepa si existen reales órdenes o disposiciones superiores en contra, petición que no se tiene en consideración, ante la ausencia del Alcalde, y ni siquiera se vota ${ }^{37}$.

La Comisión Provincial de Monumentos en su reunión de 22 de enero es advertida por varios de sus vocales del comienzo del derribo «sin formalidades»; "en su consecuencia se acordó hacer nueva protesta ante el Gobernador civil, Alcaldía de Oviedo, Dirección General de Bellas Artes y Reales Academias de la Historia y de Bellas Artes de San Fernando a fin de que se suspenda dicho derribo y en este caso, como en otros análogos, se procure la conservación de los monumentos locales que lo merezcan, como los Arcos de los Pilares, por su importante testimonio de arte de los pueblos» ${ }^{38}$. Las cartas al Ayuntamiento y al Gobernador civil van acompañadas, en el expediente municipal ${ }^{39}$, de un Ruego del Gobernador de remisión del acuerdo del derribo por parte de la Corporación municipal, ruego que es atendido de inmediato y, el 28 de enero de 1915, se remite el acuerdo de 2

36 «De ese modo, el Ayuntamiento tendrá dos beneficios el hermoseamiento de una zona tan importante y tan necesitada de facilitar su urbanización, y el ingreso de unas cuantas pesetas para ayudar á la penuria por que hoy atraviesa el Municipio. Esta reforma cuyo comienzo era profetizado con un acompañamiento de cataclismos y motines, se ha iniciado en la más completa tranquilidad». Noroeste, 12 de enero de 1915.

37 AMO: A-201 f. 15v.-20v.

38 MAA: Actas de la Comisión Provincial de Monumentos, años 1904 a 1932. Caja 83730-2.

39 AMO: 1-1-77-113. de diciembre de 1910, a falta de alguno mejor, quedando a la espera de la reunión del Ayuntamiento para contestar en forma a las alegaciones de la Comisión.

Sin embargo, ya el 25 de enero, se había tratado otra vez del derribo de los Pilares y, ante la insistencia del concejal Guisasola en su paralización, el Alcalde, don José María Cienfuegos-Jovellanos, contesta que aunque sus gestiones habían sido infructuosas había que "conjurar la crisis obrera" y no había otras obras más que el derribo y el aprovechamiento de los materiales, eso sí dejando algunos arcos "como recuerdo". Esta contestación es admitida por todos los concejales, mucho más preocupados en por qué el Alcalde había ido a Madrid sin avisar, y sólo encuentra eco en el concejal Díaz que es de la opinión de «que sean derribados todos los arcos sin excepción alguna $»^{40}$.

Como era de esperar, el derribo no se vuelve a tratar salvo para aclarar el Alcalde, en la sesión de 19 de abril de 1915, que el gasto del derribo realizado no había excedido de 3.000 pesetas y se había proporcionado trabajo a 300 obreros. Igualmente admite que no ha llegado a buen puerto ninguna gestión con los propietarios de los terrenos inmediatos quienes solo llegaron a ofrecer 300 pesetas por los tres arcos grandes ${ }^{41}$.

La Comisión Provincial de Monumentos da cuenta de la recepción, en su reunión de 10 de junio de 1915, del informe de la RAH y se acuerda que "por la Superioridad" se haga saber al Ayuntamiento que suspendan las obras de derribo y se atengan a las disposiciones legales en la materia ${ }^{42}$. Sin embargo, en las actas municipales no aparece en los meses siguientes información alguna al respecto, encontrándose la corporación sumamente ocupada en aclarar el incidente de protocolo entre el Gobernador y el Alcalde con motivo del Corpus.

Un año más tarde, la Comisión Provincial de Monumentos informa, en su sesión de 20 de enero de 1916, que por parte del Gobierno civil se ha remitido una real orden disponiendo que el acueducto de los Pilares sea declarado Monumento histórico, quedando por lo tanto subordinado a la dirección del Ministerio

\footnotetext{
AM0: A-201 f. 22r.-23r.

41 AMO: A-201 f. 89r.-v.

42 MAA: Actas de la Comisión Provincial de Monumentos, años 1904 a 1932. Caja 83730-2.
} 
de Instrucción Pública y bajo la dependencia inmediata de esta Comisión de Monumentos. Se acuerda oficiar al Ayuntamiento para que consigne en los próximos presupuestos para realizar obras convenientes en las partes que quedan $^{43}$. El Acueducto de los Pilares fue declarado Monumento histórico por Real Orden de 26 de noviembre de 1915, publicada en el Boletín Oficial del Ministerio de Instrucción Pública y Bellas Artes de 10 de diciembre de 1915, núm. 99. Curiosamente, no hay noticias de dicha real orden en las actas municipales desde noviembre de 1915 hasta finales de marzo de 1916, ni por comunicación de la Comisión de Monumentos, ni del Gobierno civil, ni de la propia Dirección General de Bellas Artes, lo que resulta extraño dada la importancia de la misma y los comentarios que en ella se vierten sobre la actuación municipal que «hace recaer sobre el Municipio de Oviedo censuras muy justificadas». En cualquier caso, el que hubiera transcurrido casi un año entre los hechos denunciados y la orden de paralización del derribo pone claramente en duda su posible efectividad.

Que la Corporación no se dio por enterada sobre la declaración de los Pilares como monumento nacional se observa claramente cuando, ante la petición del Ingeniero Jefe de la $1^{a}$ División de Ferrocarriles de información sobre si podría continuarse con el derribo del acueducto, presentada el 4 de octubre de 1917, el Ayuntamiento comienza una negociación con la Compañía del Norte sobre las condiciones para la ampliación de la estación, vías, muelles y almacenes, previos informes del arquitecto municipal. Una vez consensuados los términos del acuerdo, solo se encuentra como disposición en contra la Real Orden de 24 de enero de 1906, por lo que el propio Ayuntamiento se dirige, en junio de 1918, al Ministro de Instrucción Pública solicitando su derogación. El expediente finaliza con una comunicación del Gobierno Civil que, a su vez, remite un informe de la Dirección General de Obras Públicas que comunica que S.M. el Rey ha dispuesto que se apruebe el proyecto de ampliación de instalaciones sin esperar la autorización del Ministerio de Instrucción Pública, dado que el trámite de derogación de la orden de 1906 requiere un plazo muy largo y hay

43 MAA: Actas de la Comisión Provincial de Monumentos, años 1904 a 1932. Caja 83730-2. "urgencia", permitiendo únicamente las obras no relacionadas con el derribo ${ }^{44}$. Una vez más resulta curioso que se siga sin mencionar el carácter de monumento del Acueducto, lo que, sin duda, haría de todo punto innecesaria la derogación de una orden anterior ya sin validez alguna. En cualquier caso, si hubo contestación o no, y en qué sentido, no consta ni en los expedientes sobre la materia, ni en las actas municipales de $1919^{45}$.

\section{Cárcel Galera}

En 1916 se propone autorizar a la Diputación enajenar en pública subasta el edificio de la antigua Cárcel Galera, propiedad del Ayuntamiento y de la Diputación a partes iguales. El 9 de septiembre de 1916 se adjudica la subasta a don Ramón Martínez Cabal, que, en 1917, solicitó licencia de derribo, que le fue concedida en Sesión ordinaria de 30 de marzo de $1917^{46}$. El solar se subdividió en dos parcelas, una de ellas pasó a ser propiedad de don Rafael Plana Marqués, que construye en 1918 un edificio con planos del Maestro de Obras don Ulpiano Muñoz Zapata ${ }^{47}$. La otra parcela siguió siendo propiedad de don Ramón Martínez. Hubo que esperar a 1922 para que el arquitecto don Manuel del Busto construyera un edificio en esquina con la plaza de la Escandalera ${ }^{48}$ siguiendo la corriente regionalista en su vertiente montañesa ${ }^{49}$.

\footnotetext{
4 AM0: 1-1-103-42 y 1-1-103-48.

45 Que esta real orden fue ignorada, tal vez por desconocimiento, a lo largo del tiempo queda claro, no solo por lo sucedido en 1917, sino que, incluso, en el Decreto de 11 de febrero de 1955, del Ministerio de Educación Nacional, por el que se declara Zona monumental diferentes sectores de la ciudad de Oviedo, dice textualmente: "Hasta ahora han sido declarados monumentos en Oviedo su Catedral, el Claustro de San Vicente, la Foncalada, la Iglesia de San Tirso, las Murallas, el Palacio de Camposagrado, San Julián de los Prados, San Miguel de Lillo y Santa María del Naranco".

46 AM0: 1-1-7-52.

47 AM0: 1-1-4-73 al 75. Para profundizar en la obra de Muñoz Zapata, véase Héctor Blanco González, Arquitectura sin arquitectos en Asturias: maestros de obras y otros autores (1800-1935), Consejería de Educación, Cultura y Deporte, Oviedo, 2013, pp. 221-237.

48 AM0: 1-1-4-108.

49 Rosa María Faes, Manuel del Busto: arquitecto, $1874-$ 1948, Colegio Oficial de Arquitectos de Asturias, Oviedo, 1997, pp. 58-59.
} 


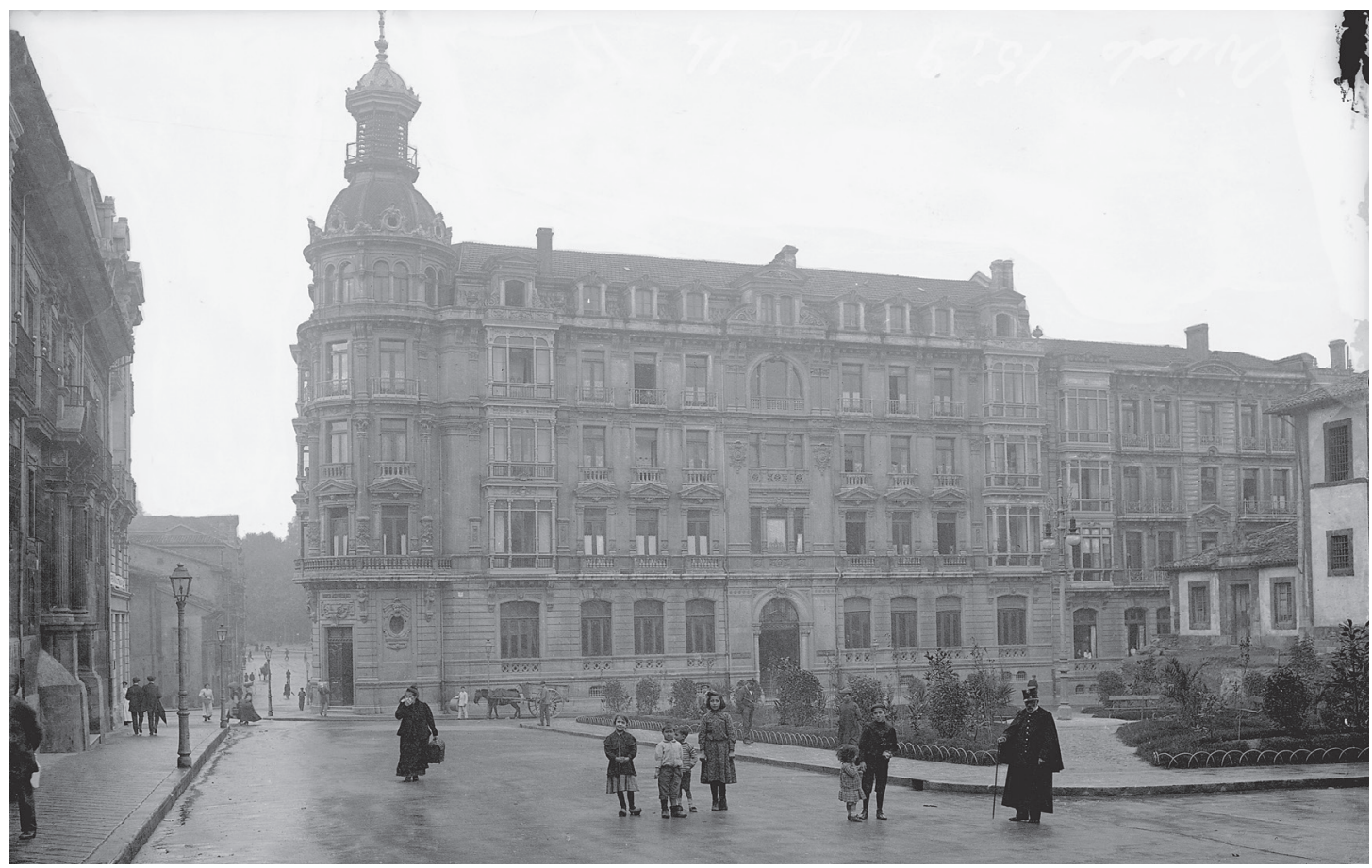

Fig. 3. Plaza de Porlier. Edificio del Banco Asturiano, construido en el solar del Colegio de San Gregorio, a la derecha Cárcel Fortaleza. Fototipia Thomas. C. 1910. AMO: P-00548.

\section{Cárcel Fortaleza}

Tres años después, el 17 de enero de 1919, se adjudica, también en pública subasta, a don José Maria Escriña González el edificio que estuvo destinado a Cárcel Fortaleza, asimismo propiedad del Ayuntamiento y de la Diputación a partes iguales ${ }^{50}$. Curiosamente, cuando todavía no habían transcurrido dos años de la subasta, el Ayuntamiento intenta volver a comprar el solar para construir las Casas Consistoriales, operación que no se lleva a efecto, entre otras razones, por el precio y las condiciones que establecen los propietarios, condiciones que, según informe del arquitecto municipal, supone un aumento de un 45\% respecto al precio por el que lo habían adquirido ${ }^{51}$.

El derribo del edificio comenzó en 1919 y, tal como se había acordado en el pliego de condiciones, la Comisión Provincial de Monu-

50 Acta del Ayuntamiento de 24 de enero de 1919 (AMO: A-205 f. 20r.). Ya con fecha 21 de junio de 1915 se había aprobado un pliego de condiciones para la subasta del edificio, subasta que no llegó a adjudicarse (AMO: A-201 f. 145v.). La subasta adjudicada fue la tercera de las presentadas e incorporaba modificaciones propuestas por los arquitectos provincial y municipal (AMO: A-204 f. 177v.-178v.).

51 AMO: 1-1-48-34. mentos supervisó las labores y recogió aquellas "piedras que aparecieran con inscripciones y restos de labores artísticas", entre ellas una inscripción que don Fermín Canella, a la sazón Presidente de la Comisión, no duda en calificar de «inscripción importantísima de Alfonso III el Magno"; asimismo se solicitó al maestro de obras encargado del derribo que, cuando completaran la demolición, realizaran «los trabajos oportunos para lograr una planta aproximada del antiguo castillo o fortaleza del mencionado monarca asturiano [Alfonso III] a fin de dilucidar un punto muy importante en la historia ovetensem ${ }^{52}$.

El solar fue finalmente comprado por la Compañía Telefónica Nacional de España, que obtiene licencia para completar su vaciado el 5 de agosto de $1927^{53}$ y comenzar a construir seguidamente el edificio central de la Compañia Telefónica con planos de don Jesús Álvarez de Meana de acuerdo con las propuestas de la arquitectura regionalista al estilo de los palacios montañeses ${ }^{54}$.

52 Actas de la Comisión de 2 de junio de 1919 y de 24 de mayo de 1920 (MAA: Actas de la Comisión Provincial de Monumentos, años 1904 a 1932. Caja 83730-2).

53 Expte. 2383/1927 (AM0: 5-2-13-15).

54 Expte. 2643/1927 (AMO: 9-2-11-1). Francisco JAVIER García Algarra, De Gran Vía al Distrito C. El patrimonio arquitectónico de Telefónica, Madrid, p. 342 


\section{Colegio de San Pedro}

El Colegio de San Pedro, o de los Verdes por el color de la beca, según nos relata $\mathrm{Ca}-$ nella ${ }^{55}$ fue fundado y dotado por el Canónigo don Pedro Suárez, en 16 de octubre de 1593, para sostener a doce colegiales que terminaran su carrera en la Universidad. Las becas eran de la dirección del Cabildo Catedral y de provisión en las casas de Heredia y Rivera, de las que descendía e! fundador. Todavía en 1888 la Capilla-oratorio del colegio de los Verdes, en la calle de Argüelles, era "pública para todos los que quieran oír misa", según indicaba un letrero en su puerta ${ }^{56}$, aunque el estado de la zona, a pesar del tránsito, debía de estar en muy malas condiciones; con un dato basta, el 3 de octubre de 1887 el Ayuntamiento había ordenado al Administrador del Colegio la colocación de aceras en las fachadas del edificio a la calle de Argüelles y Plaza del Progreso de las que carecía.

En el año 1927, el Ayuntamiento emprende gestiones para emplazar en el solar del Colegio la Casa de Correos, cuya construcción iba a comenzar en la calle de San Vicente ${ }^{57}$; finalmente, la propuesta se desestima. Unos años después, en $1931^{58}$, la Caja Asturiana de Previsión Social, figura como propietaria del edificio del Colegio y como tal solicita, y obtiene, licencia para su derribo con el fin de construir en dicho solar el edificio social de dicha Caja ${ }^{59}$. Este notable edificio de estilo racionalista, cuyo autor fue el arquitecto don Joaquín Vaquero Palacios, ${ }^{60}$

(tesis doctoral, recurso en línea: http://e-spacio.uned. es:8080/fedora/get/tesisuned:GeoHis-Fjgarcia/Documento.pdf).

55 Fermin Canella y Secades, Oviedo: Guía, Est. Tip. De Vicente Brid, Oviedo, 1888, pp. 244 y 286, e Historia de la Universidad de Oviedo y noticias de los establecimientos de enseñanza de su distrito, $2^{\text {a }}$ ed., Imprenta de Flórez, Gusano y Compañía, Oviedo, 1903, p. 9.

56 AMO: 1-1-4-20.

57 AM0: 1-1-4-30

58 En el Padrón de habitantes de 1923 constan varios estudiantes viviendo en el Colegio, mientras que en el Padrón de 1930 ya no aparece ninguna persona residiendo en el edificio (Padrones de Vecindad del año 1923 y 1930, AMO: V. 26 y 53).

59 Expte. 478/1931 (AM0: 7-1-5-12).

60 El edificio se encuentra catalogado en el Registro de obras del DOCOMOMO Ibérico (Documentación y Conservación de la Arquitectura y el Urbanismo del Movimiento Moderno). Para mayor información sobre la obra, véase José Antonio Pérez Lastra, Vaquero Palacios: arquitecto, Colegio Oficial de Arquitectos de Asturias, Oviedo, 1992, pp. 47-50 y 146-155. se comenzará a construir en el año 1934, no siendo finalizado, a causa de la guerra, hasta $1942^{61}$.

\section{Monasterio de San Vicente}

La historiografía tradicionalmente ha relacionado la fundación de la ciudad de Oviedo con el asentamiento de Máximo y Fromestano, en el año 761 en un lugar llamado Oueto (según un supuesto documento fundacional de 25 de noviembre del año 781, transmitido por copia del s. XI-XII) para fundar la basílica de San Vicente, que se vincularía a una comunidad monástica.

En los siglos posteriores el Monasterio consiguió un gran desarrollo y potencia económica gracias a las donaciones de la monarquía y la nobleza de las que fue beneficiario. El Monasterio fue ampliado y remozado en numerosas ocasiones de forma que la mayoría de los elementos medievales se perdieron.

En el siglo XI la casa seguía la Regla de San Benito, vinculándose, en 1515, a la Congregación de San Benito de Valladolid. Con los sucesivos decretos de desamortización de 1836 y 1837 , terminó la vida conventual y la iglesia tomó el carácter de parroquial; el resto del edificio fue destinado a oficinas de la Administración Civil, desfilando por sus locales, en sucesivas tandas, el Gobierno civil, la Diputación provincial, Hacienda, etc., incluso parte de sus dependencias se destinaron, en su momento, a residencia del Cuerpo de Carabineros.

El Boletín Oficial de la Provincia de Oviedo de 1 de febrero de 1915 anunciaba la apertura de un "concurso para la adquisición por el Estado de solares o edificios a derribar o aprovechar para proveer a los servicios de Correos y Telégrafos de un edificio adecuado a esta capital». Meses después, en la Gaceta de Madrid, en su número 171 de 20 de junio, se declara desierto dicho concurso por haberse desechado las cuatro proposiciones presentadas, pese a que una de ellas, la presentada por don Antonio González Mena, con el proyecto de restauración, reforma y reparación de una parte del convento de San Vicente, fue informada favorablemente por la Junta provincial de obras, pero desestimada por la Junta de Correos ya que «entre otros inconvenientes reúne el de hallarse en

\footnotetext{
61 $\quad$ Expte. 249/1934 (AM0: 17-3-44-36).
} 


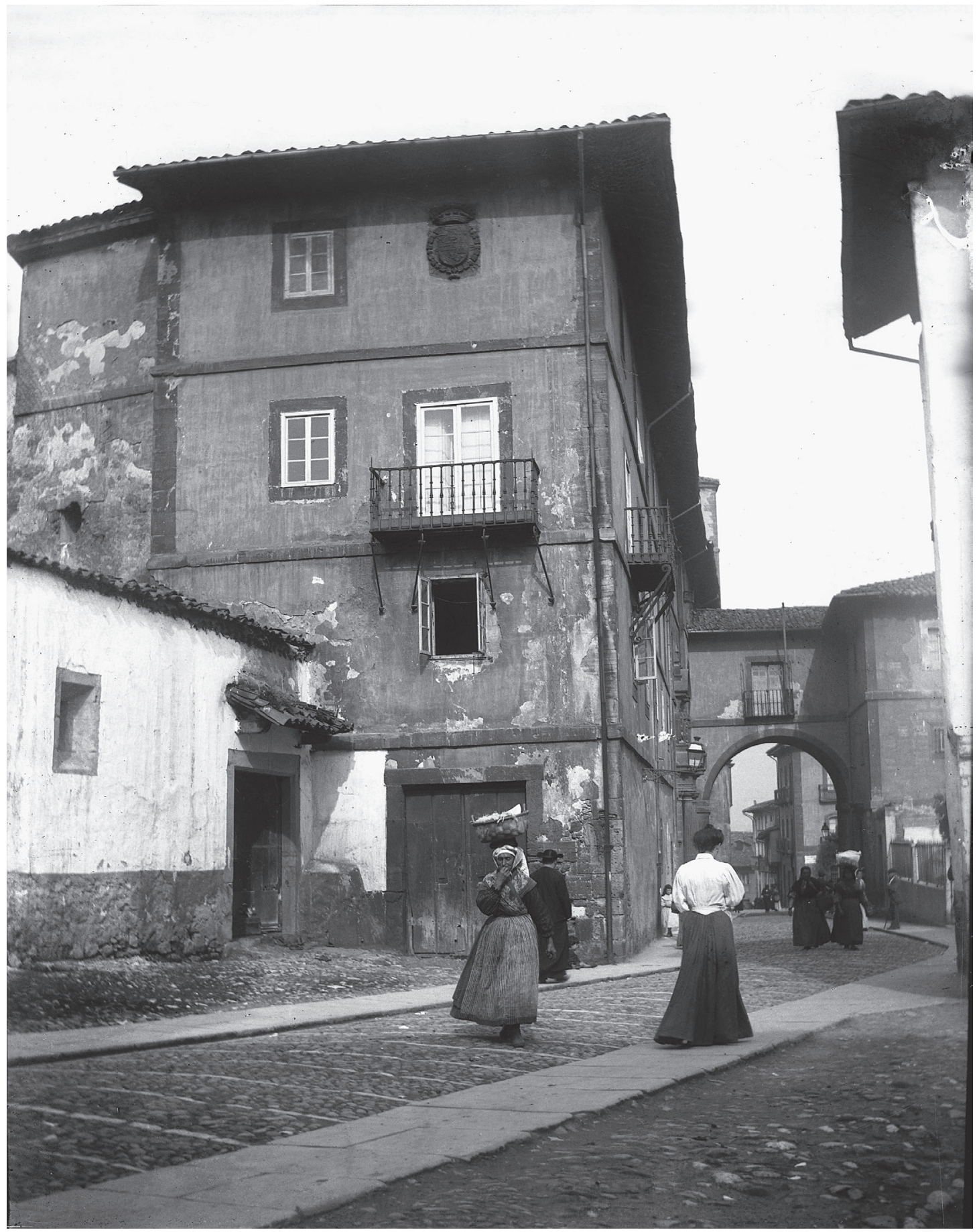

Fig. 4. Monasterio de San Vicente. c. 1900. AM0: Colección Armán, P0086. 
una zona hoy un poco decadente y que no es la más a propósito".

En la sesión ordinaria de 6 de diciembre de $1915^{62}$ el concejal Cuesta ruega al Alcalde en funciones, don Marcelino Fernández y Fernández, que se ocupe del asunto de la Casa de Correos, cuestión que había sido tratada a lo largo de los años 1914 y 1915 en varias sesiones municipales sin que se llegara a ningún resultado en concreto; la moción es secundada por otros concejales. Esta cuestión va surgiendo periódicamente en las actas municipales en los años siguientes sin que se resuelva el problema de los solares y el dinero consignado para los mismos, a todas luces insuficiente, hasta que, en la sesión ordinaria de 30 de enero de $1920^{63}$ el concejal Cuesta insta al Alcalde, don Marcelino Fernández y Fernández, que, en los dos meses que le queda de mandato, resuelva los asuntos importantes que quedan pendientes, entre ellos la Casa de Correos. El Alcalde promete intensificar sus gestiones en este tiempo y prueba de ello es la noticia aparecida en el Noroeste de 23 de febrero de 1920 que, bajo el título "Tendremos Casa Correos", da cuenta de un telegrama recibido por el Alcalde en funciones, señor Fernández Alonso, en el que don Marcelino Fernández participa de su visita al Director General de Correos quien, según cuenta, tras estudiar el asunto, pidió al Ministro de Hacienda que dictara una real orden cediendo el edificio San Vicente para, posteriormente, anunciar un concurso de anteproyectos, reunir un jurado y proceder a la subasta de las obras.

Vuelve a ser El Noroeste el que, en sucesivas ediciones, va informando del estado de la propuesta. Y así, el 10 de noviembre de 1922, recoge el anuncio efectuado por el Ministro de Fomento de haber sido aprobado el proyecto del arquitecto Menéndez Pidal para el edificio de la Casa de Correos en Oviedo, que se construirá en la parte izquierda de San Vicente, donde estuvo el antiguo Gobierno civil. Del proyecto del edificio no se conserva el expediente en el Archivo Municipal de Oviedo; conocemos que el proyecto iba firmado por dos arquitectos, Luis Menéndez Pidal y Fernando Arzadun e Ibarraran, por el dibujo de la fachada y la nota explicativa que aparece en la publicación "Catálogo ilustrado de Asturias" ${ }^{\circ}$.

\footnotetext{
AM0: A-201 f. 280r.-281r.

AMO: A-206 f. 15v.-16r.

4 Catálogo ilustrado de Asturias, PPKO, Vigo, 1925, p. 90.
}

Habrá que esperar a la edición del 23 de octubre de 1926 del Noroeste en que se vuelve a informar de la llegada al Ayuntamiento de un nuevo telegrama firmado por los concejales Pazos y Coronas, dando cuenta de las gestiones que han llevado a cabo para conocer el estado del expediente de la Casa Correos de esta capital y anunciando la salida a subasta en el mes de noviembre de las obras por un presupuesto de 600.000 pesetas.

Y en medio de tanto atraso, el Ayuntamiento y unos vecinos aportan su granito de arena a la ya de por sí confusa situación: proponen cambiar su emplazamiento de la calle de San Vicente, en terrenos propiedad del Estado, por la esquina de la plaza del Progreso y Argüelles, que ocupaba el Colegio de los Verdes, sin rescindir la subasta de las obras, ya adjudicada y cediendo el Ayuntamiento al Estado el nuevo emplazamiento. Propuesta que, finalmente, es desestimada por el propio Ayuntamiento en noviembre de $1927^{65}$.

Las obras comenzaron en mayo de 1927, siendo necesario para ello el desalojo de varias familias ("A la una de la tarde fueron arrojados los muebles de las viviendas del caserón, que pertenecían a once familias. Fue preciso el empleo de la fuerza de Seguridad, quedando á última hora de la tarde libre de moradores el antiguo convento" ${ }^{66}$ ).

Pero las dificultades no terminan ahí. Para el proyecto de la nueva Casa de Correos, el arquitecto municipal, don Francisco Casariego, informa que es preciso expropiar el solar y el pequeño edifıcio, ambos propiedad del Cabildo, que se encuentran frente a la fachada. La Comisión permanente, en sesión de 11 de noviembre de 1927, aprueba el informe, por lo que se procede a la valoración y abono de la parcela, como pasos previos al desmonte del edificio y el acondicionamiento del terreno resultante ${ }^{67}$.

Que las obras no estuvieron exentas de polémica, lo indica el hecho de que los propios arquitectos, Arzadun y Menéndez Pidal, saltan a la palestra publicando una carta en los periódicos defendiendo su proyecto y exculpándose del retraso en las obras, que achacan a varios motivos: hasta 1927 no se subastaron las obras, hubo que esperar al desalojo de las personas

\footnotetext{
65 AM0: 1-1-4-30 y Acta de la Comisión de Policía Urbana de 15 de noviembre de 1927 (AMO: V. 2 p. 53)

66 El Noroeste, 10 de mayo de 1927

67 Expte. 2933/1927 (AMO: 4-6-51-15).
} 
que vivían allí, existió una campaña de prensa para variar el emplazamiento, y, finalmente, de vuelta al solar original, se encontraron diferencias entre el tamaño del solar y la rasante de lo que se les había informado, de forma que el proyecto tuvo que ser rehecho por ellos «total y gratuitamente» ${ }^{68}$.

Las obras siguieron apareciendo con regularidad en la prensa; a veces por la aparición de restos arqueológicos en el derribo de esa parte del Monasterio, como la carta que publican en La Voz de Asturias y Región, el 9 de marzo de 1929, don Aurelio del Llano y Roza de Ampudia, Delegado de Bellas Artes, y don Luis Menéndez Pidal, dando cuenta del hallazgo de un león gótico y varias piedras que, según ellos, por sus características formarían parte de las basas de columnas y una de ellas completaría "con la existente en el Museo, la cancela de la iglesia de Lillo".

De nuevo es la prensa quien indica que no todo va como debiera, y así La Voz de Asturias, el 4 de febrero de 1930, ofrece un titular sensacionalista: "Los servicios afectos al Cuerpo de Telégrafos van adquiriendo tal amplitud, que muy pronto habrá de considerarse incapaz la nueva casa que se construye en San Vicente». Efectivamente, con el tiempo se verá lo acertado de la previsión, de forma que ya no se puede postergar más la decisión del uso del edificio y, el 8 de septiembre de 1933, el periódico Región adelanta que tras una visita del Director General de Comunicaciones y de un arquitecto del estado, se ha llegado a la conclusión de que el edificio de San Vicente no reúne las condiciones precisas. Ese mismo día, en el acta de la sesión del Ayuntamiento se faculta al Alcalde y a un concejal para que acudan al Obispado para que pospongan la venta del edificio del Círculo Mercantil ${ }^{69}$ hasta que en Madrid se decidan si quieren ese edificio para «Palacio de Comunicaciones» $^{70}$.

Sobre el uso dado al edificio tras la renuncia a establecer en el mismo la Casa de Correos no

68 La Voz de Asturias, 16 de marzo de 1928. Quiero agradecer a don José Antonio Fernández de Córdoba su desinteresada ayuda al facilitarme numerosos datos aparecidos en la prensa sobre San Vicente, fruto de sus años de estudio sobre este tema.

69 El Círculo Mercantil fue adquirido en pública subasta por las Damas de Acción Católica tras la disolución de la Sociedad (El Noroeste, 7 de junio de 1925 y ss.).

70 Acta del Ayuntamiento de 8 de septiembre de 1933 (AMO: A-225 f. 64r.). se sabe nada con certeza hasta la inauguración, a finales de 1947, en dichos locales del Centro Coordinador de Bibliotecas de Asturias ${ }^{71}$.

En la escalera que conduce a la Biblioteca del actual Museo Arqueológico, se conserva un escudo que estaba situado en la fachada Sur de San Vicente, como se observa en las frecuentes postales existentes del «Caserón de San Vicente» antes de la demolición. Se trata de un escudo de los reyes de España de 1580 a 1668 ya que incorpora las armas de Portugal (Felipe II, Felipe III, Felipe IV y Carlos II). Están representadas las armas de Castilla, León, Aragón, Sicilia, Granada, Austria, Borgoña moderna, Borgoña antigua y Brabante. Sobre el todo dos escudetes: uno, en el punto de honor, que es de Portugal y el otro, en el ombligo del escudo, con las armas de Flandes, partido del Tirol. Exteriormente el collar del Toisón de Oro y la corona real ${ }^{72}$.

\section{Plazuela de la Catedral}

Canella, en su Guía de Oviedo de 1887, describe en pocas palabras la Plaza de la Catedral como sigue: «Frente a la Santa Iglesia. Bien reducida para que tan magnífico monumento pueda ser debidamente contemplado. En Oviedo, población donde tanto escasean las espaciosas plazas de otras capitales, éste debió ser, aunque costoso, un pensamiento predilecto de las corporaciones municipales para expropiar las casas de enfrente» ${ }^{73}$.

Es de suponer que la idea no se materializara, corporación tras corporación, por el elevado coste de una operación urbanística de esta envergadura; sin embargo, el 13 de mayo de 1924, exactamente a las 18:30 h., don Luis $\mathrm{Mu}-$ ñiz Miranda, ante el notario don Secundino de

${ }^{71}$ La fecha exacta de inauguración del Centro no figura en el texto de la Memoria del año 1947, sin embargo, en un pie de foto se señala la inauguración conjunta de los locales del Centro Coordinador y de la Biblioteca Fray Jerónimo Feijoo, y este último lo sitúan el 30 de noviembre de 1947. Memoria del Centro Coordinador de Bibliotecas de Asturias: (año de 1947), Diputación Provincial de Oviedo, Oviedo, 1948, p. 21.

72 Matilde Escortell lo señala como perteneciente a los Borbones, lo que no sería posible dada la presencia del escudo de Portugal. Matilde Escortell Ponsoda, Catálogo de heráldica y epigrafía medieval y moderna del Museo Arqueológico, Museo Arqueológico, Oviedo, 1981, p.78 y lam. I.

73 Fermín Canella y Secades, Oviedo: Guía, Est. Tip. De Vicente Brid, Oviedo, 1888, p. 101. 


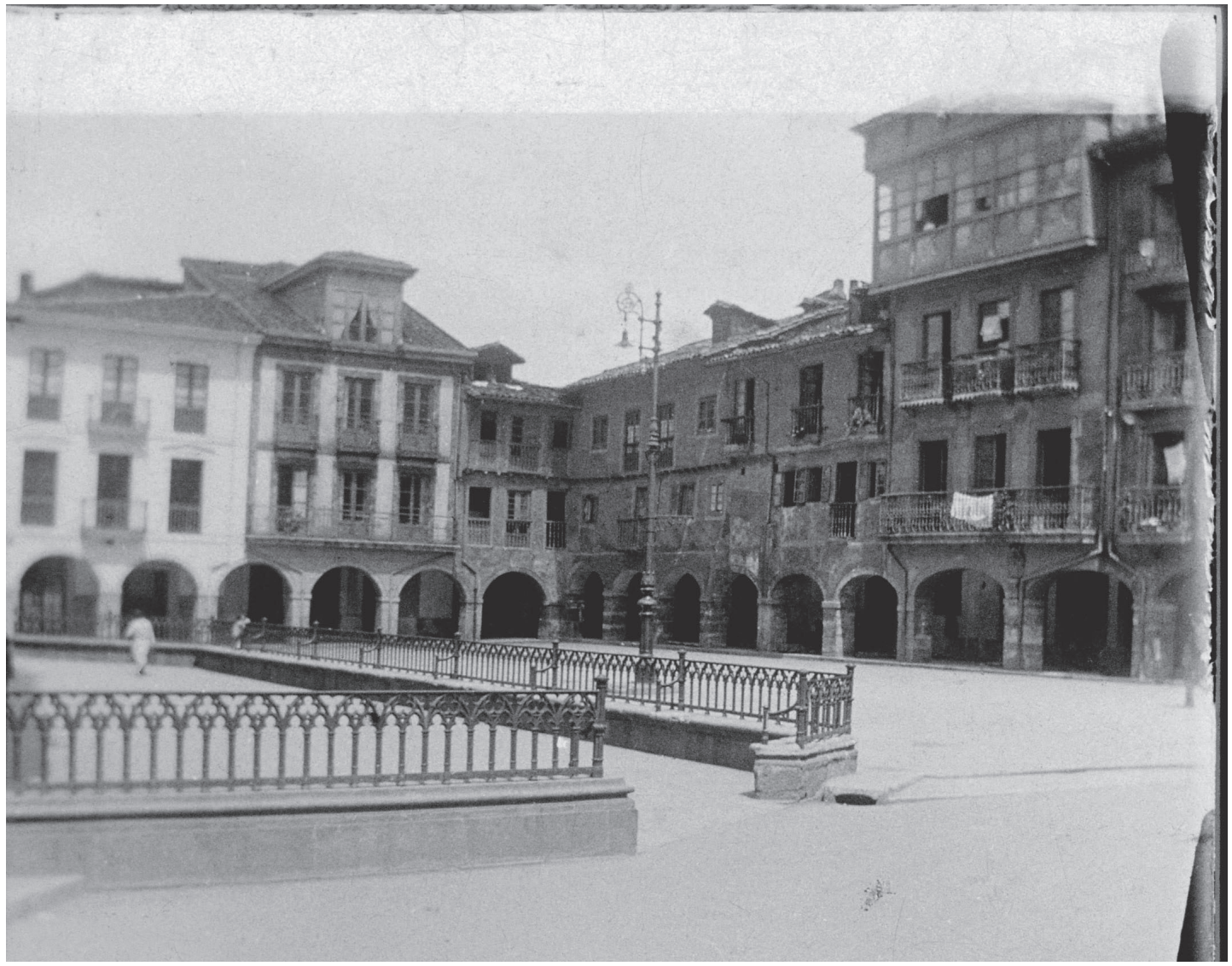

Fig. 5. Plazuela de la Catedral. c. 1920. AM0: Colección Armán, P0149.

la Torre, otorgaba un testamento que destaparía la caja de los truenos al legar al Ayuntamiento de Oviedo una serie de bienes que poseía en el concejo de Oviedo con la obligación de destinar el importe total que se obtuviera de sus ventas a mejoras urbanas, especialmente a las expropiaciones necesarias para la apertura y formación de una gran plaza delante de la catedral. Y aunque don Luis Muñiz no murió hasta el día 20 de enero de 1927, la "maquinaria" se puso en marcha.

Inmediatamente, el 26 de mayo de 1924, el alcalde don José Cuesta presenta una moción para que se proyecte el ensanche de la plazuela con la expropiación de los edificios necesarios $^{74}$, moción que es aprobada en Comisión Permanente de 30 de mayo de $1924^{75}$.

Ante el debate que rápidamente suscitan las voces que clamaban por el derribo inmediato sin más y el plano del arquitecto municipal don Francisco Casariego, de fecha agosto de 1924,

74 Expte. 698/1924 (AMO: 8-4-21-23).

75 AMO: A-211 f. 40r. en el que se señalaba la zona a expropiar que comprendía todos los edificios frente a la Catedral llegando hasta la plaza de la Balesquida y calle de San Juan ${ }^{76}$, el concejal José María González del Valle intentó poner algo de cordura y seriedad en la cuestión presentando una moción en el mes de octubre, en la que, tras reflexionar sobre las razones a favor y en contra del ensanche de la Plazuela de la Catedral, solicita que, antes de tomar cualquier decisión, se oiga el parecer de autoridades y personas cualificadas en estas cuestiones, y que, se tome la decisión que se tome, se elaboren ordenanzas municipales apropiadas para zonas especiales. Su moción no está exenta de lírica:

"Un gran literato asturiano de corazón y sobre todo un enamorado de Oviedo lo describió muchas veces en sus obras con el acierto de un conocedor que unía a su gran talento un alma de poeta. Y ninguna de sus descripciones tan sencilla ni precisa como el adjetivo con que lo nombraba: Vetusta. Todos los carbayones he-

76 AMO: 1-1-13-31. 
mos aceptado el sobrenombre porque nos damos cuenta del valor exacto de este adjetivo cuando se aplica a Oviedo. Aquí no hay, en efecto, ninguna maravilla arquitectónica; todo se reduce a unos cuantos palacios señoriales que se yerguen entre montones de casuchas viejas y mal alineadas que se levantan sobre angostos soportales. Todo esto es lo que imprime a Oviedo ese singular encanto que tan luego echa de ver cualquier mediano observador que recorra sus calles."

La Comisión Permanente de 30 de octubre de 1924 aprueba la moción y se solicita el parecer de la Real Academia de Bellas Artes de San Fernando, Academia de Bellas Artes de San Salvador de Oviedo, Comisión Provincial de Monumentos, don Luis Menéndez Pidal, don Luis Menéndez Pidal y Álvarez, don José Ramón Zaragoza, don Víctor Hevia y don Nicanor Piñole ${ }^{77}$.

Las contestaciones son variopintas ${ }^{78}$ : para Hevia, uno de los elementos más distintivos de las catedrales españolas son las plazoletas irregulares ante ellas, en las que se respira intimidad y recogimiento, por lo que se opone al derribo. Los Pidal, padre e hijo, escriben un carta conjunta con Zaragoza exponiendo que, aunque no tengan valor de arte, son típicas construcciones, adecuadas al clima, con cierta belleza y que con su misma pequeñez hacen aparecer más grandiosa la catedral; por otra parte, consideran que, a mayor distancia, lo que se vería mejor de la catedral serían sus faltas de terminación, y, además, la torre perdería los puntos de vista de las callejas circundantes. Finalizan proponiendo que mejor se dediquen a conservar lo poco que queda tras los últimos derribos y citan San Isidoro, San Francisco, San Juan, etc.

A favor del derribo se alinean la Academia de Bellas Artes de San Salvador de Oviedo, porque la torre es "bellísima" y ahora no se ve bien, y aprovechan para citar a Canella, y la Comisión Provincial de Monumentos, que expone que «a juicio de la Comisión no existe razón ni fundamento alguno de carácter histórico-artístico que aconsejen la conservación de las expresadas viejas edificaciones, dado su deplorable aspecto y carencia absoluta de arte, que empequeñecen y dificultan además la observación en todas las proporciones y hermo-

77 AMO: A-211 f. 126r.

78 AMO: 1-1-13-31. sos detalles de nuestra Catedral». De paso opina que también deberían desaparecer los edificios enclavados a la derecha de la plazuela.

Por su parte, el Cabildo envía su parecer, ex motu proprio, y añade un argumento más al ya tan traído de la mejor visión de la catedral: en este caso es la necesidad de contar con mayor espacio para los actos religiosos, al ser el actual «insuficiente, a todas luces, para contener la multitud de personas que, cuando tiene lugar alguna solemne procesión... allí se apiñan, allí se estrujan", ni que sea tampoco suficiente para las tropas que esperan las salidas de las procesiones.

Para complicar todavía más la situación, don Francisco Bailly solicita licencia para reformar y distribuir su casa que da a las calles San Juan y Sanz y Forés, que se encontraba en ruinas ${ }^{79}$. El informe del arquitecto municipal expone la necesidad de solucionar primero la cuestión pendiente de las expropiaciones de la plazuela de la catedral, dado que esta casa es uno de los edificios afectados, pero que, puesto que esta casa tenía el problema añadido de encontrarse fuera de alineación, se planteara directamente a su propietario la posibilidad de su expropiación; propuesta que es aprobada por la Comisión permanente de 27 de noviembre de $1924^{80}$. Al estar de acuerdo el propietario comenzaron las conversaciones que se prolongaron tanto en el tiempo de forma que en diciembre de 1925 Bailly vuelve a presentar solicitud de licencia, esta vez con planos firmados por el arquitecto Manuel Bobes Díaz ${ }^{81}$, solicitud que se le concede ante la incapacidad por parte del Ayuntamiento de hacer frente a los gastos de una expropiación y para evitar los perjuicios ocasionados por la demora al propietario ${ }^{82}$.

Pese a este acuerdo oficial, el alcalde, don José María Fernández Ladreda, continúa las negociaciones con Bailly y consigue llegar a un acuerdo satisfactorio para las dos partes: la expropiación con un aplazamiento del pago, abonando el ayuntamiento un interés del 5,5\% hasta que se realice el pago. La propuesta es presentada por el alcalde en sesión de Comisión permanente de 6 de mayo de $1926^{83}$, y, una vez explicadas las razones que le llevaron a obrar

\footnotetext{
Expte. 222/1924 (AM0: 8-4-21-24).

AM0: A-211 f. 142v.-143r.

81 AMO: 1-1-63-3.

82 Acta del Ayuntamiento de 14 de enero de 1926 (AMO: A-215 p. 164).

83 AMO: A-215 f. 324r.
} 
por su cuenta, es aprobado. El definitivo acuerdo de compra se toma en el Pleno de 8 de mayo de 1926, y es formalizado por escritura de 20 de mayo de 1926 ante el notario don Cipriano Álvarez Pedrosa ${ }^{84}$. Finalmente el derribo comenzó el 14 de junio de 1926 y el importe de los materiales vendidos procedentes del derribo de la casa ascendió 2.073 pesetas que se ingresaron en las arcas municipales ${ }^{85}$.

En el ínterin, el 8 de marzo de 1925, don Manuel Gallego, por aquel entonces concejal del Ayuntamiento de Oviedo, miembro de la Comisión de Policía Urbana y capitán de ingenieros, publica un extenso artículo en La Voz de Asturias con un significativo título: "Las reformas del casco urbano de Oviedo ¿debe ensancharse la Plazuela de la Catedral?». En dicho artículo expone las razones a favor del ensanche, que somete a crítica: en cuanto a las condiciones de higiene se refiere, tal vez se mejorasen, pero no necesariamente; que las condiciones de vialidad también pueden mejorarse notablemente, pero también se podría hacer sin el ensanche, y en cuanto a las condiciones de belleza: «iquién puede dudar que se perderían totalmente las muchas típicamente ovetenses que hoy tiene la Plazuela!». Terminaba comparando esta actuación con las llevadas a cabo de esta índole en otras ciudades españolas, como Burgos y Segovia, para concluir que San Salvador de Oviedo no era el mismo caso y no soportaría "un examen minucioso" de su fachada. El final tiene un carácter claramente exhortativo: "En Oviedo hay mucho que remediar y amplio campo donde desarrollar las modas urbanísticas, pero no deben olvidarse las buenas reglas del arte cívico ni dejar perder con indiferencia lo poco que va quedando del patrimonio artístico local, que si no es grandioso todo él, es bello, sugeridor y representativo, mereciendo el cuidado y cariño de cuantos saben apreciarlo".

No es casualidad que días después la Comisión Permanente, en sesión de 12 de marzo de $1925^{86}$ a la vista de un informe de la Comisión de Policía Urbana que proponía la desestimación del ensanche por carecer de base económica y de las opiniones encontradas de las personalidades e instituciones consultadas, se plantee abandonar el proyecto. El alcalde,

\footnotetext{
84 AMO: A-214 f. 8r.-v., expte. 222/1924 (8-4-21-24) y expte. 698/1926 (8-4-21-1).

85 AMO: Expte. 698/1926 (8-4-21-1) y 1-1-63-4.

86 AMO: A-213 f. 41r.-v.
}

don José María Fernández Ladreda, insiste en la expropiación y expone la incongruencia en la que se caería ante el reciente acuerdo de expropiación de la casa de Bailly. Finalmente se acuerda que la cuestión retorne a la Comisión de Policía Urbana para un estudio más detenido. Este acuerdo dio lugar a que se presentaran, por una parte, un informe de la Comisión de Policía Urbana en el que explica detalladamente su postura, adoptada ante la falta de una valoración clara de las expropiaciones y de un anteproyecto de ensanche por parte de la Oficina de obras municipal, y la demora en la contestación por parte de la Real Academia de Bellas Artes de San Fernando que consideran imprescindible; y, por otra parte, la actitud del alcalde Fernández Ladreda, quien presenta un voto particular en el que, frente al argumento de la falta de liquidez, proclama: «no se trata de resolver hoy, se trata sí de ir dibujando el Oviedo de un mañana más venturoso...pensando en que nuestros sucesores tengan un panorama más amplio, más risueño y más artístico aún, si es posible que el que tenemos nosotros", y propone un pleno extraordinario en el que se estudie el prohibir otorgar licencias de reconstrucción en las casas comprendidas en la zona del ensanche hasta que se llegue a un acuerdo definitivo, y que se trate de nuevo el caso particular de Bailly ${ }^{87}$.

El Pleno extraordinario se celebra el 28 de marzo de 1925 y, tras exponer detenidamente los antecedentes existentes, el informe y el voto particular, el debate que se suscita llega a un punto tal, que se suspende la sesión por un breve tiempo para intentar llegar a un acuerdo. Una vez reanudada ésta, se manifiesta haber llegado a un acuerdo con dos puntos; el primero, que el arquitecto municipal estudie un plan de ensanche, y que en el pleno en que se trate esta cuestión, el concejal que lo desee pueda presentar también un plan de reconstrucción, y, el segundo, que se intente convencer al señor Bailly de la conveniencia de retirar su petición de edificación, bien a la espera de la alineación oficial, bien por aceptar su expropiación ${ }^{88}$.

No pasan ni tres meses cuando aparece en escena un nuevo elemento: el Gobierno Civil da traslado de una Real Orden con la resolución de la Comisión Central de Sanidad local que, en su sesión de 7 de junio de 1925, se hace eco del

\footnotetext{
87 AMO: 1-1-13-31.

88 AMO: A-212 f. 15r.-17v.
} 
informe de la Real Academia de Bellas Artes de San Fernando en que valora la zona de interés artístico extraordinario con sus casas porticadas, por lo que comunica al Ayuntamiento que desista del derribo «mientras razones más poderosas que las aducidas no lo justifiquen".

La Comisión Permanente en sesión de 4 de junio se da por enterada y lo traslada, a su vez, al Pleno de 18 de junio en el que la Corporación no puede por menos que manifestar su extrañeza ante el comunicado arguyendo, entre otras cosas, que sólo se había pedido información desde el punto de vista artístico a la Real Academia de San Fernando, por lo que no entienden cómo acabó el asunto en las manos de Gobernación y de la Junta Central sanitaria, y acuerdan que continúe el estudio del ensanche de la plazuela ${ }^{89}$.

Ante la falta de acuerdo entre las posturas existentes, el alcalde Fernández Ladreda presenta, en enero de 1926, una moción en la que suaviza su postura inicial y propone el derribo de un solo edificio, logrando así un pasillo desde Porlier que permitiría la visión de la catedral sin obstáculos conservando las edificaciones de la plaza, sugiriendo, incluso, la construcción de soportales en las traseras de los edificios para una mayor estética ${ }^{90}$. La Comisión Permanente, casualmente en la misma sesión en la que aprueban la edificación del señor Bailly, aprueba la moción y acuerda que el arquitecto municipal haga el proyecto a la mayor brevedad ${ }^{91}$.

La brevedad no fue tanta, ya que el proyecto del arquitecto municipal, don Enrique Rodríguez Bustelo, lleva fecha de 9 de mayo de 1927 ${ }^{92}$; en él, siguiendo las teorías de Camillo Sitte (Viena, 1843 - 1903) (33 $^{93}$ y partiendo de la base de que todo el proyecto giraba sobre la necesidad de dar a la catedral una mejor visibilidad, presenta varias soluciones. Las soluciones 2, 3, 4 y 5, que consistirían en el derribo de la plazuela y su reorganización colocando manzanas de vivienda en distintas zonas para dar forma, más o menos, cuadrada a la plaza resultante, él mismo las considera inapropia-

AM0: 1-1-13-31, A-213 f. 115r.-v. y A-212 f. 23r.-v.

90 Expte. 698/1925 (AM0: 9-2-12-2).

91 Acta del Ayuntamiento de 14 de enero de 1926 (AMO: A-215 pp. 166-167).

92 Expte. 698/1925 (AM0: 9-2-12-2).

93 Arquitecto austriaco teórico del urbanismo, cuya obra cumbre "Construcción de ciudades según principios artísticos o El arte de construir las ciudades" se publicó en español en 1926. das y las desecha. Lo mismo opina de la solución A: el derribo de la plazuela dejando libre todo el espacio, ya que perjudicaría a la catedral al tener una superficie exagerada la plaza que achicaría las proporciones de la fachada e iría en contra de los principios de una solución artística. Finalmente, presenta la solución 1, que considera la más adecuada: se trazaría una nueva manzana paralela al Casino, aunque, sorprendentemente, no alineada con él y así "encuadrar" la catedral, que respondería a los principios estéticos; para comprobar lo correcto de las proporciones presenta un estudio de la Plaza de la Constitución y de la fachada de San Isidoro y de la fachada de la Catedral.

El informe es aprobado por la Comisión de Policía Urbana ${ }^{94}$ y la Comisión Permanente ${ }^{95}$, quedando constituida una comisión formada por dos concejales y los arquitectos municipales con el fin de entablar negociaciones con los distintos propietarios para las expropiaciones y la reconstrucción del Monte de Piedad que, anteriormente, ocupaba el número 9 de la calle de Sanz y Forés.

Por fin, el 28 de marzo de 1928, el arquitecto municipal presenta el informe definitivo, con un presupuesto de $654.177,85$ pesetas, que es aprobado por la Comisión Permanente de 30 de marzo de $1928^{96}$, acordándose que se haga presupuesto extraordinario y se comience su tramitación. Como complemento a este proyecto, la Comisión de Policía Urbana, pensando que las ordenanzas municipales de construcción vigentes no darían la respuesta adecuada a la estética pretendida en el ámbito de la catedral, redacta unas "Ordenanzas especiales para la edificación en la Plaza de Alfonso II el Casto", que son aprobadas en la sesión de 13 de abril de 1928 de la Comisión Permanente, y publicadas en el Boletín Oficial de la Provincia, número 98 de 1 de mayo de 1928. Transcurrido el plazo de reclamaciones sin que se presentara ninguna, son aprobadas definitivamente por el Pleno extraordinario celebrado el 25 de octubre de 1928, remitiendo una copia de las mismas al Gobernador civil ${ }^{97}$.

La publicación en el Boletín Oficial de la Provincia, número 89 de 20 de abril de 1928,

\footnotetext{
94 Acta de la Comisión de Policía Urbana de 21 de junio de 1927 (AMO: V. 2 p. 9)

95 Acta de la Comisión Permanente de 24 de junio de 1927 (AMO: A-216 f. 261r.-v.)

96 AMO: A-217 f. 224v.-225r.

97 Expte. 3155/1928 (AMO: 17-3-40-13).
} 
del anuncio de exposición pública del «Proyecto de urbanización y ensanche de la Plazuela de la Catedral», dio comienzo a la incoación de una serie de expedientes ${ }^{98}$ en los que se recogen, sin orden ni concierto, alegaciones, recursos, acuerdos, informes, proyectos y expropiaciones, que se tramitarán en los años siguientes de una forma un tanto precipitada, dando lugar incluso a declarar lesivos algunos de estos acuerdos la propia Comisión especial de responsabilidades del Ayuntamiento de Oviedo, moción desestimada por la Comisión Permanente en sesión de 9 de enero de 1931 tras la lectura del informe de los arquitectos municipales.

Veamos algunas de esas alegaciones: la alegación del Marqués de Santa Marina de Garizo protestando por la pérdida de la plazuela de San Juan frente a sus propiedades (desestimada en Pleno de 22 de agosto de 1928 basándose en el informe del abogado consistorial); la propuesta de la Junta Provincial de Sanidad de continuar la alineación con Porlier (desestimada en sesión de la Comisión Permanente de 26 de octubre de 1928), y la protesta de la Cámara de la Propiedad Urbana que, dos años después de la propuesta de alineaciones de la Junta de Sanidad (en sesión de 19 de agosto de 1930) acusa al Ayuntamiento de extralimitarse en sus funciones al no asumir dicha propuesta, y hace explícita esta protesta "con objeto de salvar su responsabilidad moral». El Ayuntamiento saca en este caso todas sus baterías y presenta dos informes en su contra: el primero del Abogado Consistorial, en que estima que la propuesta de la Junta de Sanidad era de carácter no preceptivo, sino de consejo, por lo que no era necesario su cumplimiento, y la del Secretario, que añade su asombro ante la falta de reclamaciones oficiales por parte de la indignada Cámara en el período de alegaciones, y el hecho de que su Presidente, siendo concejal, ni siquiera emitiera su voto en contra en las sesiones del pleno y permanente en las que se ha tratado este asunto. Como era de esperar la Comisión Permanente, en sesión de 29 de agosto de 1930, rechaza la propuesta ${ }^{99}$.

98 AMO: Expte. 698/1925 (9-2-12-2), Expte. 698/1926 letra I (9-2-12-7), Expte. 698/1928 (9-1-3-1), Expte. 3155/1928 (17-3-40-13), Expte. 698/1929 letra B (92-12 bis-2), Expte. 698/1929 letra D (9-1-5-21), Expte. 28/1930 (9-1-5-20), Expte. 698/1930 letra G (7-1-2-3), Expte. 698/1930 (9-1-7-17) y Expte. 136/1935 (12-7327-1).

99 AMO: A-221 f. 103v.-104v.
Las negociaciones para las expropiaciones comienzan y, ante las diferencias en las tasaciones por parte de los peritos de los propietarios y los peritos municipales, se nombra un tercer perito "neutral", en este caso el arquitecto don Julio Galán y González Carvajal, que fija las cantidades a abonar a los propietarios que son admitidas por todos, salvo, curiosamente, uno de los casos en los que su peritaje era inferior al del perito de la Administración y, por tanto, no se aprueba. Y así se cierran las negociaciones sucesivamente, en 1929 (doña Ampara Carral) y 1930 (Marqués de San Feliz, Hermanos Galán, Hermanos Armán, don Policarpo Herrero, Herederos de don Juan Amor y doña Cristina Caballero). En el caso del Marqués de San Feliz, de uno de sus inmuebles, la cantidad no es abonada hasta noviembre de 1932, ya que, hasta esta fecha, la casa se encontraba con inquilinos.

Por otra parte, mientras el Ayuntamiento tramitaba expropiaciones a su aire, la Comisión Provincial de Monumentos, en sesión de 3 de abril de 1930, da cuenta de un oficio recibido de la Dirección General de Bellas Artes que comunica una Real Orden de 27 de marzo de 1930 que notifica que, al haberse comenzado a incoar expediente para la declaración de monumentos histórico-artístico de la plaza de la catedral, con especial referencia a la manzana que el Ayuntamiento quiere demoler, con informe favorable de la Real Academia de San Fernando, se advierta a la autoridades locales este hecho y se impida el derribo de edificaciones en dicho lugar. Pese a esta Real Orden, la Comisión Provincial de Monumentos, tras releer su acta de 27 de diciembre de 1924, se ratifica en lo acordado, es decir, a favor del derribo total de la plazuela ${ }^{100}$.

La lectura de la Real Orden en la sesión de la Comisión Permanente de 4 de abril de 1930 produce asombro, dado que habían pasado cinco años ya desde que se pidió el parecer de la Real Academia de San Fernando; se acuerda que el Alcalde y el Teniente-Alcalde se desplacen inmediatamente a Madrid para iniciar las gestiones necesarias para revocar dicha Real Orden ${ }^{101}$. Efectivamente, tres semanas después el Alcalde da cuenta de sus gestiones a la Comisión Permanente y que tiene la impresión que

\footnotetext{
100 MAA: Actas de la Comisión Provincial de Monumentos, años 1904 a 1932. Caja 83730-2.

101 AMO: A-219 f. 245v.-246r.
} 
la Real Orden va a ser revocada ${ }^{102}$. Sus presentimientos se confirman con la comunicación de la nueva Real Orden de 9 de agosto del Ministerio de Instrucción Pública y Bellas Artes relativa al derribo. Efectos inmediatos son, entre otros, la premura en la tramitación del proyecto del Monte de Piedad «habiendo cesado la causa que impedía concederle la licencia de construcción en virtud de R.0. 27 Marzo 1930» ${ }^{103}$.

$\mathrm{Y}$ no puedo por menos que detenerme en la construcción de este edificio del Monte de Piedad por las especiales circunstancias que la rodean. Hago un breve resumen de su tramitación: en principio es el único caso en el que se reconstruye un edificio, para la misma función, en otro solar en la misma plaza, en este caso para Monte de Piedad, y se construye, además, en la única manzana que se crea en el proyecto de ensanche diseñado por el arquitecto municipal, señor Rodríguez Bustelo, manzana que, al no atenerse a las alineaciones ni del Casino, ni de la Audiencia, suscita desde el principio, como ya se indicó, grandes rechazos. Por otra parte, también se señaló anteriormente que la Comisión especial de responsabilidades del Ayuntamiento de Oviedo consideró el precio de venta de dicho solar como lesivo al ser una cantidad irrisoria, moción desestimada por el informe de los arquitectos municipales, don Enrique Rodríguez Bustelo y don Francisco Casariego, que habían sido también los responsables de la tasación ${ }^{104}$. Tampoco se tuvo en cuenta la solicitud de Víctor Galán de aplazamiento de los derribos y paralización del vaciado del solar para el Monte de Piedad hasta que no hubiera contestación a sus recursos ante el Consejo de Ministros y los Ministerios de Instrucción y Gobernación; solicitud rechazada por la Comisión Permanente en sesión de 9 de mayo de 1930 ateniéndose al informe del arquitecto municipal, señor Rodríguez Bustelo ${ }^{105}$. Finalmente, en el año 1930, tras muchos dimes y diretes, y contando incluso con la ayuda del propio Marqués de San Feliz, que contribuyó

102 Acta de la Comisión Permanente de 25 de abril de 1930 (AMO: A-219 f. 230r.).

103 Actas de la Comisión Permanente de 22 y de 29 de agosto de 1930 (AM0: A-219 f. 91r. y 104 r.-v.).

104 Expte. 698/1930 (AM0: 7-1-7-17). A manera de anécdota señalar que, aunque el informe está firmado por los dos arquitectos, el hecho de que en su redacción abunden los "a mi juicio" indica claramente la mano de una sola persona en su redacción, no siendo aventurado pensar que fue el arquitecto Rodríguez Bustelo.

105 Expte. 698/1930 letra G (AM0: 7-1-2-3) económicamente para lograr la expropiación de la casa número 5 de la plazuela que impedía el comienzo de las obras ${ }^{106}$, se comienza la construcción del edificio con proyecto de un arquitecto que, casualidad de la vida, a estas alturas nos resulta más que familiar: don Enrique Rodríguez Bustelo ${ }^{107}$.

Que la manzana creada en la plazuela iba a dar problemas queda reflejado no sólo en los expedientes relativos al monte de Piedad, sino también en el resto de los solares que comprendía. Y así el expediente para adaptar los edificios y solares existentes a la nueva manzana con sus peculiares alineaciones, no comienza su tramitación hasta 1935 finalizando sin solucionar, en $1946^{108}$. La clave del asunto fue el empeño por parte del arquitecto municipal, señor Rodríguez Bustelo, en derribar la casa número 8, que era de propiedad municipal, y reunificar los solares resultantes mediante permuta y compra de los propietarios de la casa colindante número 7 . El problema es que, al principio, los herederos de José Cima García no se pusieron de acuerdo en la compra y permuta y, posteriormente, cuando en el año 1941 la propiedad pasó a propiedad de los Hijos de Luis Gomez Morán y se retomaron las negociaciones, las condiciones fueron consideradas inaceptables por parte de los propietarios. Al final, el Ayuntamiento terminó demandado, ya que, al proceder al derribo de la casa número 8 , se ocasionaron daños a la medianera, entre ellos unas terribles humedades. El expediente termina con un informe del arquitecto municipal, don Gabriel de la Torriente, que más que informe es una desiderata, puesto que habla de la desaparición de las humedades una vez que se construya en ese solar, por lo que "todos los trastornos quedarán resueltos en fecha próxima”. La realidad es que la casa se derribó, con sus humedades, en $1968^{109}$ sin que en el solar contiguo se hubiera construido. Finalmente, la manzana se completó en el año 1986 con la construcción de un edificio firmado por los arquitectos don José Benito Díaz Prieto y don José Lada Álvarez, siendo el resultado final de forma similar, pero no idéntica, a la proyectada por un cambio

\footnotetext{
106 Acta de la Comisión Permanente de 8 de agosto de 1930 (AMO: A-221 f. 79v.-80r.)

107 Expte. 28/1930 (AMO: 9-1-5-20)

108 Expte. 136/1935 (AM0: 12-7-327-1)

109 Expte. 618/1968 (AM0: 12-7-182-34)
} 
en la alineación en la calle del Águila y la eliminación del chaflán de la calle del Águila con la plaza.

Parte de los arcos de la plazuela se salvaron de su destino como material de desecho, al ser adquiridos por la Sociedad Popular Ovetense para formar un soportal en el nuevo edificio de oficinas de la Fábrica de Gas, situada en la calle Paraíso. En el proyecto del arquitecto don Miguel García-Lomas, de 1932, son seis los arcos que se utilizan ${ }^{110}$, aunque finalmente fueron siete los arcos recuperados, al variarse el proyecto primitivo sin que exista constancia de la solicitud de un modificado de obras.
La urbanización de la plaza se completó con una fuente proyectada por el arquitecto municipal, señor Rodríguez Bustelo, en julio de 1934. Los trabajos de urbanización, fuente incluida, se adjudicaron al contratista don Belarmino Cabal el 30 de noviembre de 1934; las obras comenzaron el 28 de junio de 1935. Tras el parón de la Guerra Civil, se retoma, en julio de 1938, el proyecto, añadiendo a las obras que faltaban las reparaciones de los desperfectos ocasionados por los bombardeos. Las obras fueron recepcionadas en julio de 1940, fecha en la que podemos dar por finalizada la parte principal de lo que se denominó proceso de ensanche de la plazuela de la catedral ${ }^{111}$. 